\title{
Very Low Density Lipoprotein Cholesterol Measurement
}

National Cancer Institute

\section{Source}

National Cancer Institute. Very Low Density Lipoprotein Cholestero/ Measurement. NCI Thesaurus. Code C105589.

The determination of the amount of very low-density lipoprotein cholesterol present in a sample. 